\section{Coastal zone ecology}

The Coastline. Edited by R. S. K. Barnes. Pp. 356. (Wiley: Sussex, New York and Sydney, 1977.) £12.50; $\$ 24.50$.

BY a nice piece of timing, the publication date of this book coincided with the First European Ecological Symposium on Ecological Processes in Coastal Environments at Norwich, where it was exhibited by the publishers. It certainly caught the attention of the conference participants who seemed to like what they saw; so did I. Having now had the opportunity to read it in some detail, my opinion has not changed.

The stated purpose of the book is to contribute to our understanding of the coastline's ecology and physiography in relation to land-use, management and the pressures to which it is subject. To meet this objective, the editor has brought together a team of contributors who have done an admirable job in condensing a relatively large amount of information into one very readable volume. After an introductory chapter on problems and pressures, there follow thirteen chapters, each concerned with one fairly uniform group of habitats. Seven chapters describe predominantly aquatic environments (lagoons, estuaries and foreshores) and six cover terrestrial environments (reclaimed land, cliffs, dunes and shingle). A common structure has been adopted for each chapter: a summary of the ecological and geomorphological processes, characteristic features and pressures, recommendations for methods of study, particular uses, and finally suggestions for conservation and management policies. Coastline management is dealt with in more detail in a concluding chapter.

Many of the examples given are of British coastal areas, but others are from mainland Europe and some from as far afield as Australia. The diagrams which illustrate the various sections are generally good but the reproduction of the (fortunately few) photographs is very poor. There are errors, but those I found are mostly minor spelling mistakes. However, inaccuracies do occur: for example, on p144, it is erroneously stated that the Nature Conservancy Council do not own land. I consider that there are also some errors of omission. Current proposals for energy generation from a Severn Barrage or wave energy converters are not included; the effect of either on the coast would probably be considerable.
Although thermal pollution is mentioned, the possible damaging effects on plankton by its entrainment in cooling water systems is not discussed. The introduction of alien species, which has already led to a great many changes in some ecosystems, is dealt with rather superficially. It would have been valuable if some developing ideas about various ecosystems were included, such as the probable part played by diatoms and some invertebrates in stabilising sediments by their mucus secretions. It is surprising how little is said about ecological and conservation evaluation of coastal ecosystems, surely an essential step in formulating any management proposals. Perhaps more would have been included on this subject had A Nature Conservation Review (for review, see Nature, 269, 271, 1977) been published a few years earlier.

\section{Atmospheric highlights}

Earth's Aura. By Louise B. Young. Pp. 305. (Alfred A. Knopf: New York, 1977.) $\$ 12.95$.

THIs is a book about some of the highlights of the history of atmospheric exploration, about the effect of man's activities on the atmosphere and about the effect of climate on man. In the first chapter we are taken up with pioneering balloonists rising to unbelievable heights in flimsy baskets as the main structures of the various regions of the atmosphere are introduced. The second and third chapters introduce us to clouds and cloudseeding experiments, and describe thunderstorms by recounting the drama of Franklin's classic kite experiment and the experience of a German glider pilot caught in a cumulonimbus. The delicate balances which control some of the atmosphere's chemistry (including the ozone problem) are introduced in the next three chapters. The enormous variety of winds, jet streams and waves come next; then optical phenomena, the solar wind and the atmospheres of the planets are dealt with in the same dramatic style. Modern speculations about the way the climate may change are discussed in a final chapter.

It is a fascinating account written in an enthusiastic, dramatic, sometimes gripping, style. The material has been effectively selected so that the book is not only very readable but also informative. Some beautiful colour pictures from space are included in the collection of ten illustrations in the centre of the volume.

Both the general reader and the
As stated in the concluding chapter, we still have to reply heavily on a descriptive approach to many ecosystems, as not enough is known to quantify them; we still have some way to go before we can be confident in our predictive capabilities as coastal managers. In relation to this, it would have been valuable to have had an expansion of the last chapter which concerned itself more fully with an appraisal of the state of the art. Nevertheless, I strongly recommend this book to those concerned with coastal management as well as to anyone seeking a lead into the study of this fascinating zone.

R. Mitchell

R. Mitchell is a Marine Biologist with the Chief Scientist's Team at the Nature Conservancy Council, Huntingdon, UK.

specialist will be left with a new perspective on the environment and a new enthusiasm for the continuing quest. "Weather is probably the most dominant factor in determining the quality of human existence", we are reminded, "but although we have set foot on the Moon, have identified organic molecules in the tenuous dust of interstellar space and measured the speed of galaxies a billion light years away, we still do not understand the intricate interplay of forces that move the earth's weather".

On the whole, the book presents the present staite of knowledge in an accurate way. The emphasis of one or two of the chapters, however, tends to leave the reader with a misleading impression. One might have wished for instance that alongside the dramatic description of the 1952 London fog, the far-reaching changes brought about by the 1957 Clean Air Act might have been described. Too much attention is also given to the rather speculative area of the influence on the climate of sunspot cycles and the like, whereas virtually no mention is made of the ocean/atmosphere interaction and feedback processes involving the Arctic or Antarctic ice which are probably of much greater importance.

The cover describes the book as science writing at its best: the adventures and discoveries of the past, the problems that still face us. I centainly enjoyed reading it; it must be one of the best popular science books which deals with the atmosphere.

Further, for a well printed book of 700 pages and some colour jilustrations, the book is moderately priced.

\section{J. T. Houghton}

J. T. Houghton is Professor of Atmosphere Physics at the Clarendon Laboratory, Oxford, UK. 